\title{
OPEN The use of spent coffee grounds and spent green tea leaves for the removal of cationic dyes from aqueous solutions
}

\author{
Tomasz Jóźwiak ${ }^{1 \bowtie}$, Urszula Filipkowska ${ }^{1}$, Joanna Struk-Sokołowska ${ }^{2}, K$ Kamil Bryszewski ${ }^{1}$, \\ Karol Trzciński ${ }^{1}$, Joanna Kuźma ${ }^{1}$ \& Monika Ślimkowska ${ }^{1}$
}

This study aimed to examine sorption effectiveness of cationic dyes: Basic Red 46 (BR46) and Basic Violet 10 (BV10) onto spent coffee ground (CG) and spent green tea leaves (GTL). The scope of the study included, i.a.: sorbent FTIR spectra analysis, determination of $\mathrm{pH}$ effect on dye sorption effectiveness, analysis of dye sorption kinetics, and determination of maximal sorption capacity of the sorbents. The effectiveness of BR46 sorption on the sorbents tested was the highest at $\mathrm{pH} 6$ and that of BV10 at $\mathrm{pH}$ 3. Both sorbents caused changes in solution $\mathrm{pH}$ during the sorption process, due to the system tending to reach the $\mathrm{pH}$ value approximating the $\mathrm{pH}_{\mathrm{ZPC}}\left(\mathrm{pH}_{\mathrm{PZC}}=7.55\right.$ for $\mathrm{CG}$ and $\mathrm{pH}_{\mathrm{PZC}}=7.05$ for $\mathrm{GTL}$ ). The time needed to reach BR46 and BV10 sorption equilibrium onto $C \mathrm{G}$ and $\mathrm{GTL}$ ranged from 180 to $240 \mathrm{~min}$. The intramolecular diffusion model demonstrated that the sorption of cationic dyes onto CG and GTL proceeded in three phases differing in the intensity and duration. The maximal sorption capacity of CG reached $179.4 \mathrm{mg} / \mathrm{g}$ for BR46 and $59.3 \mathrm{mg} / \mathrm{g}$ for BV10. The sorption capacity of GTL was lower and reached $58.0 \mathrm{mg} / \mathrm{g}$ for BR46 and $26.7 \mathrm{mg} / \mathrm{g}$ for BV10.

Post-production wastewater from the textile, tanning, or paper industries can contain significant amounts of dyes. Part of these dyes can pervade the natural environment because of the still imperfect technologies for wastewater decolorization. Dyes present in natural waters block the access of sun-rays to aquatic plants, thus inhibiting the photosynthesis process. In this respect, the most adverse to the natural environment seem to be cationic dyes, as even in very minor quantities $(<1 \mathrm{mg} / \mathrm{mL})$, they effectively colorize water, significantly decreasing its transparency. The reduction of the primary production and oxygen synthesis by autotrophs can lead to the aquatic ecosystem's breakdown. Therefore, possibly the most effective methods for dye removal from wastewater should be employed to prevent the risk of environmental degradation. Currently produced synthetic dyes are sparingly biodegradable; hence industrial wastewater containing these dyes is rarely treated using biological methods. The decolorization of post-production waters is usually conducted with various physicochemcial methods, like e.g., oxidation, coagulation, membrane processes, or sorption. It is commonly believed today that dye sorption offers one of the simplest and safest methods for wastewater decolorization.

The sorption process consists in binding one substance (sorbate) by another substance (sorbent). Its costs depend primarily on sorbent price, while its effectiveness is largely determined by sorbent type. The most common commercial sorbents include materials based on activated carbons, which exhibit a high sorption effectiveness toward most of the dyes available on the market. The good sorption properties of these materials are due to, i.a., very large specific surface area, approximating $1000 \mathrm{~m}^{2} / \mathrm{g}$. Activated carbons are usually sourced from solid fossil fuels or lignocellulosic plant biomass. Because of their stepwise and energy-consuming production (dehydration, carbonization, activation), they are usually very costly, which is their greatest drawback. This prompts the search for their cheaper substitutes.

Today, the raw materials for the production of unconventional sorbents are most often searched for among waste materials from the agri-food industry. They usually include fragments of plant biomass unsuitable for consumption left after the processing of cereals, vegetables, or fruits. Literature works present results of research into the sorption properties of such biomaterials as, e.g., fruit skins (bananas ${ }^{1}$, citrus fruits: oranges, mandarins, grapefruits, or lemons ${ }^{2}$, passion fruits ${ }^{3}$, apples ${ }^{4}$ ), or vegetable peels (of e.g. cucumbers, garlic ${ }^{5}$, potatoes ${ }^{6}$ or fava

${ }^{1}$ Department of Environmental Engineering, University of Warmia and Mazury in Olsztyn, Warszawska St. 117a, 10-957 Olsztyn, Poland. 'Department of Environmental Engineering Technology, Bialystok University of Technology, Wiejska St. 45E, 15-351 Bialystok, Poland.『email: tomasz.jozwiak@uwm.edu.pl 


\begin{tabular}{|l|l|l|}
\hline Name & Basic Red 46 (BR46) \\
\hline Structural formula & $321.4 \mathrm{~g} / \mathrm{mol}$ & $479.0 \mathrm{~g} / \mathrm{mol}$ \\
\hline Molecular weight & azo dye (“single azo dye") & xanthene dye \\
\hline Dye class & $530 \mathrm{~nm}$ (The calibration curve was prepared at $\mathrm{pH}$ 7) & $554 \mathrm{~nm}$ (The calibration curve was prepared at $\mathrm{pH}$ 7) \\
\hline Absorption maximum $\left(\lambda_{\max }\right)$ & Dyeing textiles, paper, leather \\
\hline Uses & Dyeing leather, paper, fabrics & $\begin{array}{l}\text { Toxic, fluorescent, carcinogenic; can induce skin and eye allergies, and gastrointestinal } \\
\text { problems }\end{array}$ \\
\hline Harmfulness & Toxic, mutagenic, carcinogenic ${ }^{22}$ & \\
\hline
\end{tabular}

Table 1. Characteristics of Basic Red 46 and Basic Violet 10.

beans ${ }^{7}$ ). Other sorbents used for wastewater decolorization include leaves and stems of plants (mango ${ }^{8}$, banana tree $^{9}$, maize ${ }^{10}$ ), nutshells (e.g. peanuts ${ }^{11}$, hazelnuts ${ }^{12}$, coconuts, ${ }^{13}$, walnuts, and almonds ${ }^{14}$ ), or husks of cereal grains $\left(\right.$ rice $^{15}$, wheat ${ }^{16}$, or oats ${ }^{17}$ ). Most of the tested plant biomass-based sorbents showed very good sorption capability towards cationic dyes due to the high contents of polysaccharides and lignins. The greatest advantage of the waste plant biomass is, however, its common availability, which makes its inexpensive.

Examples of the widely available waste plant biomass include also spent coffee grounds and spent green tea leaves. Their vast availability stems from the extremely high popularity of beverages made of them (coffee and green tea), which are consumed in very large quantities. The annual global production of coffee (Coffea arabica) reaches 9-10 million tonnes ${ }^{18}$, whereas that of green tea approximates 2 million tonnes ${ }^{19}$. The relatively high contents of polysaccharides and lignins in the spent coffee grounds and spent green tea leaves $(>50 \%$ d.m.) indicate their potentially high capability for binding cationic dyes.

This study aimed to examine the sorption effectiveness of cationic dyes popular in the industry (Basic Red 46 and Basic Violet 10) onto spent coffee grounds and spent green tea leaves.

\section{Materials}

Raw materials used to produce sorbents. The sorbent based on the spent coffee grounds (CG) was produced from coffee (Coffea arabica) beans purchased at a local market. The coffee grains were "medium roasted" (10 min at a temp. of $230^{\circ} \mathrm{C}$ ) and then comminuted in a ceramic mortar to the particle size of 1-3 mm. The comminuted grains were brewed for $5 \mathrm{~min}$ (temp. of $90^{\circ} \mathrm{C}$ ). The average contents of cellulose, hemicellulose, and lignins in the brewed coffee (Coffea arabica) grains were: $12.4 \%, 39.1 \%$, and $23.9 \%$, respectively ${ }^{20}$.

The sorbent based on the spent green tea leaves (GTL) was prepared from leaves of Chinese green tea $\mathrm{Bi}$ Luo Chun (Camellia sinensis var. sinensis), purchased in a local tea shop. The leaves were brewed for $3 \mathrm{~min}$ at a temperature of $80^{\circ} \mathrm{C}$. The average contents of polysaccharides and lignins in the brewed green tea leaves were: cellulose $-58.8 \%$, hemicellulose $-22.2 \%$, and lignin $-5.5 \%{ }^{21}$.

Use of plants parts in the present study complies with international, national and/or institutional guidelines.

Cationic dyes. The dyes were provided by a dye producing plant Boruta-Zachem SA (Zgierz, Poland). Their characteristics is presented in Table 1.

Chemical reagents. The following chemical reagents were used in the study:

Sulfuric acid $2 \mathrm{M}$ solved solution (POCH S.A., Poland) - (sorbent preparation/purification).

Hydrochloric acid 35-37\% a.p. (POCH S.A., Poland) - (solution pH correction).

Sodium hydroxide a.p. (POCH S.A., Poland) - (solution $\mathrm{pH}$ correction, sorbent preparation/purification).

Laboratory equipment. The following laboratory equipment was used in the study:

HI $110 \mathrm{pH}$ meter, HANNA Instruments, Poland-(solution $\mathrm{pH}$ correction).

Multi-Channel Stirrer MS-53M, JEIO TECH, Korea-(dye sorption analyses).

UV-3100 PC spectrophotometer, VWR spectrophotometers, Canada-(determination of dye concentration in the solution).

FT/IR-4700LE FT-IR Spectrometer with single reflection ATR attachment-JASCO INTERNATIONAL, Japan-(preparation of sorbent FTIR spectra). 


\section{Methods}

Preparation of sorbents. The used, comminuted coffee grounds and green tea leaves were rinsed with deionized water (till colorless filtrate). Afterward, they were dried in a dryer $\left(105^{\circ} \mathrm{C}\right)$ and sieved through laboratory screens with mesh diameters of 1.0 and $2.0 \mathrm{~mm}$. The fraction of grounds and leaves with particle diameters of 1-2 mm was kept in a $2 \mathrm{M}$ solution of sulfuric VI acid for $24 \mathrm{~h}$, then drained and washed with deionized water till the neutral $\mathrm{pH}$ of the filtrate. Afterward, the coffee grounds/green tea leaves were placed in a $2 \mathrm{M}$ solution of sodium hydroxide for $24 \mathrm{~h}$. Afterward, they were drained and rinsed with distilled water until neutral $\mathrm{pH}$ of the filtrate. Thus prepared spent coffee grounds (CG) and spent green tea leaves (GTL) were stored in a cooler at a temperature of $4^{\circ} \mathrm{C}$.

Analyses of $\mathrm{pH}$ effect on dye sorption effectiveness. Sorbent doses of $1.00 \mathrm{~g} \mathrm{~d} . \mathrm{m}$. were weighed into a series of conical flasks $(300 \mathrm{~mL})$ using a technical scale. Then, earlier prepared dye solutions $(200 \mathrm{~mL})$ with the concentration of $50 \mathrm{mg} / \mathrm{L}$ and $\mathrm{pH}$ values of the subsequent solutions reaching: 2.0/3.0/4.0/5.0/6.0/7.0/8.0/9.0/ $10.0 / 11.0$, were added to the flasks. The flasks with the solutions were placed on a magnetic stirrer (150 r.p.m.) for $120 \mathrm{~min}$. Afterward, samples of the solutions $(10 \mathrm{~mL})$ were collected with an automatic pipette to earlier prepared test tubes. The dye concentration in the samples was determined with the spectrophotometric method (at the wavelengths of $554 \mathrm{~nm}$ for BV10 and $530 \mathrm{~nm}$ for BR46). Determinations were performed using $10 \mathrm{~mm}$ quartz measuring cuvettes. The calibration curve for both dyes was prepared at the $\mathrm{pH}$ 7. The solutions of dyes showed no changes both in UV-Vis absorbance and the position of the $\lambda_{\max }$ point at different $\mathrm{pH}$ values (in the range of $\mathrm{pH} 2-11$ for BV10 and $\mathrm{pH} 2-8$ for BR46) (Supplements 1, 2).

Analysis of dye sorption kinetics. The sorbents (CG or GTL) were weighed in doses of $10.0 \mathrm{~g}$ d.m. into a series of beakers $(2500 \mathrm{~mL})$. Then, dye solutions $(2000 \mathrm{~mL})$ with sorption $\mathrm{pH}$ optimal for each dye (established based on analyses from "Analyses of $\mathrm{pH}$ effect on dye sorption effectiveness" section) and concentrations of: $50 \mathrm{mg} / \mathrm{L}, 200 \mathrm{mg} / \mathrm{L}$, and $500 \mathrm{mg} / \mathrm{L}$ for Basic Red 46; or $10 \mathrm{mg} / \mathrm{L}, 50 \mathrm{mg} / \mathrm{L}$, and $200 \mathrm{mg} / \mathrm{L}$ for Basic Violet 10, were added to the beakers. The beakers were placed on multi-station magnetic stirrers (150 r.p.m.). In the set time intervals (i.e., after: $0,10,20,30,45,60,90,120,150,180,210,240$, and $300 \mathrm{~min}$ ), 5-mL samples were collected from the solutions with an automatic pipette. The dye concentration in the samples was determined with the method described in "Analyses of $\mathrm{pH}$ effect on dye sorption effectiveness" section.

Analysis of the maximal sorption capacity. The sorbents (CG or GTL) were weighed in portions of $1.00 \mathrm{~g}$ d.m. to conical flasks $(300 \mathrm{~mL})$, which were also filled with dye solutions having the concentrations of $10-1000 \mathrm{mg} / \mathrm{L}$ (for BR46) or 10-500 mg/L (for BV10) and the optimal pH (established based on analyses performed in "Analyses of $\mathrm{pH}$ effect on dye sorption effectiveness" section). Next, the flasks were placed on a multistation magnetic stirrer (150 r.p.m.) for the time needed to reach the sorption equilibrium (established based on the analyses performed in "Analysis of dye sorption kinetics" section). Once the sorption equilibrium had been reached, $10 \mathrm{~mL}$ of the solution was collected from the flasks using a pipette to determine the concentration of dye left in the solution after the sorption process.

Calculation methods. The amount of dye bound on the sorbent was calculated from Eq. (1):

$$
\mathrm{Q}_{\mathrm{S}}=\left[\left(\mathrm{C}_{0}-\mathrm{C}\right) \times \mathrm{V}\right] / \mathrm{m} \text {. }
$$

$\mathrm{Q}_{\mathrm{S}}$ - mass of adsorbed dye $[\mathrm{mg} / \mathrm{g}], \mathrm{C}_{0}$ - initial dye concentration $[\mathrm{mg} / \mathrm{L}], \mathrm{C}$ - the concentration of dye left in the solution after the sorption process $[\mathrm{mg} / \mathrm{L}], \mathrm{V}$-solution volume [L], M-sorbent mass [g].

The results of analysis on the kinetics of BR46 and BV10 sorption onto CG and GTL were described using the pseudo-first order model (2), pseudo-second order model (3), and the intramolecular diffusion model (4) (which allows determining the number and intensity of sorption phases).

$$
\begin{aligned}
\Delta \mathrm{q} / \Delta \mathrm{t} & =\mathrm{k}_{1} \times\left(\mathrm{q}_{\mathrm{e}}-\mathrm{q}\right), \\
\Delta \mathrm{q} / \Delta \mathrm{t} & =\mathrm{k}_{2} \times\left(\mathrm{q}_{\mathrm{e}}-\mathrm{q}\right)^{2}, \\
\mathrm{q} & =\mathrm{k}_{\mathrm{id}} \times \mathrm{t}^{0.5} .
\end{aligned}
$$

$\mathrm{q}_{\mathrm{e}}$-equilibrium amount of sorbed dye [mg/g], Q-instantaneous mass of adsorbed dye [mg/g], $\mathrm{k}_{1}$ —sorption rate constant in the pseudo-first order model [1/min], $\mathrm{k}_{2}$ - sorption rate constant in the pseudo-second order model $[\mathrm{g} /(\mathrm{min} \mathrm{mg})], \mathrm{k}_{\mathrm{id}}$ - sorption rate constant in the intramolecular diffusion model $\left[\mathrm{mg} / \mathrm{g} \mathrm{min}{ }^{0.5}\right]$, $\mathrm{t}$ - sorption time [min].

Experimental data from analysis of the maximal sorption capacity was described using: Langmuir 1 model (5), Langmuir 2 model (6), and Freundlich model (7).

$$
\begin{gathered}
\mathrm{q}_{\mathrm{e}}=\left(\mathrm{q}_{\max } \times \mathrm{K}_{\mathrm{C}} \times \mathrm{C}\right) /\left(1+\mathrm{K}_{\mathrm{C}} \times \mathrm{C}\right), \\
\mathrm{q}_{\mathrm{e}}=\left(\mathrm{b}_{1} \times \mathrm{K}_{1} \times \mathrm{C}\right) /\left(1+\mathrm{K}_{1} \times \mathrm{C}\right)+\left(\mathrm{b}_{2} \times \mathrm{K}_{2} \times \mathrm{C}\right) /\left(1+\mathrm{K}_{2} \times \mathrm{C}\right),
\end{gathered}
$$




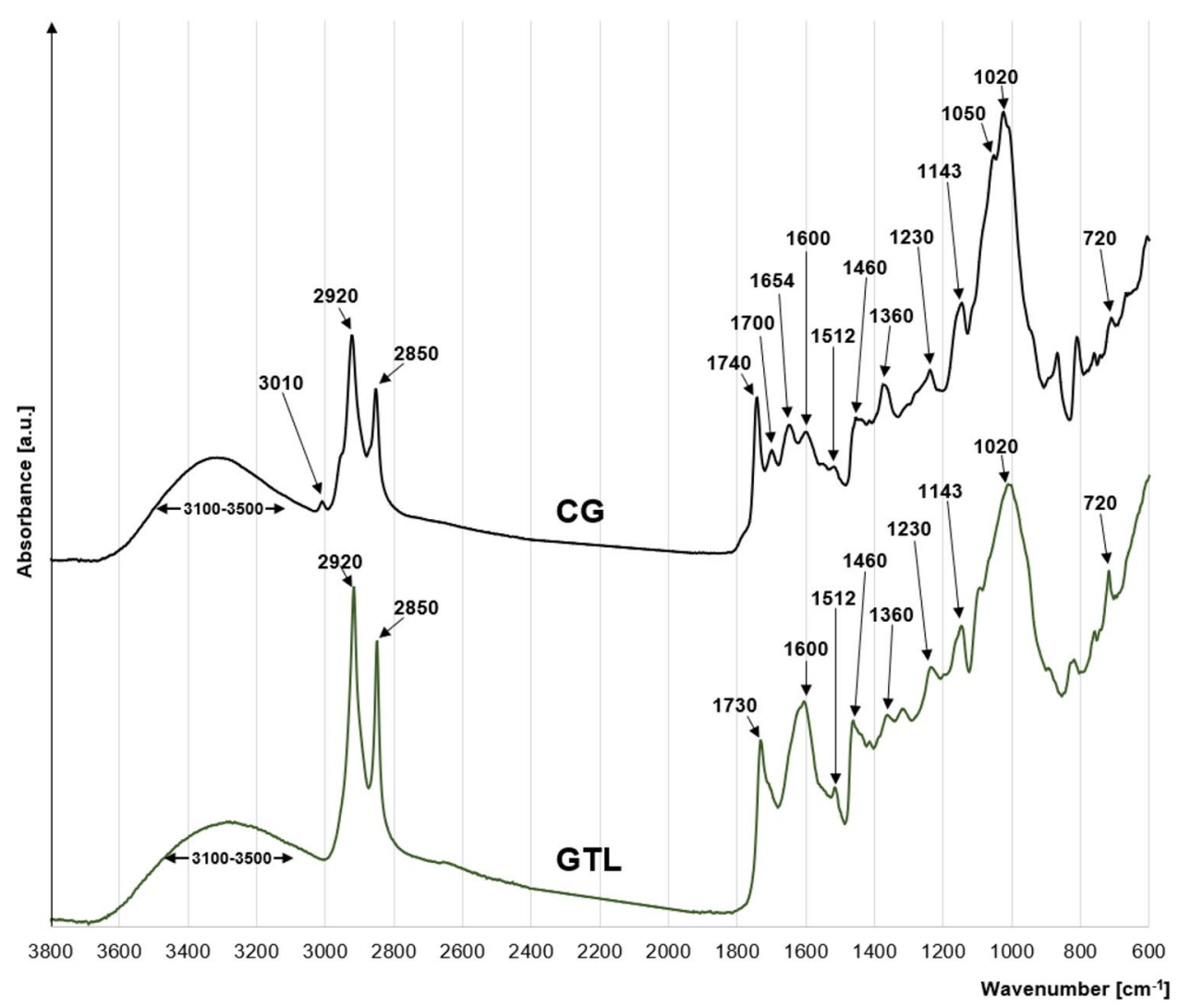

Figure 1. FTIR spectra of CG and GTL.

$$
\mathrm{q}_{\mathrm{e}}=\mathrm{K} \times \mathrm{C}^{\mathrm{n}} .
$$

$\mathrm{q}_{\mathrm{e}}$ - equilibrium amount of sorbed dye $[\mathrm{mg} / \mathrm{g}], \mathrm{q}_{\max }$-maximal capacity of the monolayer [mg/g], $\mathrm{b}_{1}$-maximal capacity of type I active sites in the monolayer [mg/g], $b_{2}$ - maximal capacity of type II active sites in the monolayer [mg/g], $\mathrm{K}_{1} / \mathrm{K}_{2}$ - constants in the double Langmuir equation [L/mg], $\mathrm{K}$-sorption equilibrium constant in the Freundlich equation, $\mathrm{C}$ - the concentration of dye left in the solution after the sorption process $[\mathrm{mg} / \mathrm{L}]$, $\mathrm{n}$-heterogenicity parameter (Freundlich model).

\section{Results and discussion}

FTIR analysis of sorbents. The CG and GTL spectra present peaks typical of the lignocellulosic plant biomass. A wide band at $3200-3400 \mathrm{~cm}^{-1}$ points to the stretching of the $\mathrm{O}-\mathrm{H}$ bond of a hydroxyl group and to the presence of hydrogen bridges (Fig. 1). Distinct peaks at $2920 \mathrm{~cm}^{-1}$ and $2850 \mathrm{~cm}^{-1}$ correspond to the symmetrical stretching of $-\mathrm{CH}_{3}$ and asymmetrical stretching of $-\mathrm{CH}_{2-}$, and indicate lipid presence in material structure ${ }^{24}$. Peaks at $1730 \mathrm{~cm}^{-1}$ (GTL) and $1740 \mathrm{~cm}^{-1}$ (CG) correspond to the vibrations of a carbonyl bond $(\mathrm{C}=\mathrm{O})$ of the ester functional groups typical of hemicelluloses ${ }^{25-27}$. In turn, the peaks at $1600 \mathrm{~cm}^{-1}, 1512 \mathrm{~cm}^{-1}$, and $1230 \mathrm{~cm}^{-1}$ are attributable to $\mathrm{C}=\mathrm{C}$ bonds of guaiacol aromatic ring, typical of lignins ${ }^{28}$. The peaks noticeable at $1460 \mathrm{~cm}^{-1}$ (the bending of $-\mathrm{CH}_{3}$ and $-\mathrm{CH}_{2}-$ ), $1360 \mathrm{~cm}^{-1}$ (the asymmetrical bending of $\left.-\mathrm{CH}_{3}\right)^{27,29}$, and $720 \mathrm{~cm}^{-1}$ (the rocking/swinging of $-\mathrm{CH}_{2}-$ ) are typical of lignins and cellulose. In turn, the peaks at $1020 \mathrm{~cm}^{-1}, 1050 \mathrm{~cm}^{-1}$, and $1143 \mathrm{~cm}^{-1}$ are attributable to $\mathrm{C}-\mathrm{O}-\mathrm{C}$ bond of the aromatic ring of polysaccharides ${ }^{30}$ (Fig. 1).

The peak visible at $3010 \mathrm{~cm}^{-1}$ only in the case of CG probably corresponds to the stretching of the $=\mathrm{C}-\mathrm{H}$ bond, whereas the peak at $1700 \mathrm{~cm}^{-1}$ reflects the stretching of the $\mathrm{C}=\mathrm{O}$ bond belonging to the carboxyl group of organic acid. The peak at $1654 \mathrm{~cm}^{-1}$ points to the presence of the $\mathrm{N}-\mathrm{H}$ bond of caffeine $\mathrm{e}^{28}$. In the case of GTL, the peak at $1654 \mathrm{~cm}^{-1}$ is, probably, obscured by a large peak at $1600 \mathrm{~cm}^{-1}$ ( $\mathrm{C}=\mathrm{C}$ bond) (Fig. 1).

The effect of $\mathrm{pH}$ on the effectiveness of dye sorption onto CG and GTL. In the initial pH range of $2-6$, the effectiveness of BR46 sorption onto CG and GTL increased along with $\mathrm{pH}$ increase, while at $\mathrm{pH}>6$ it decreased negligibly. The greatest changes in BR46 sorption effectiveness were noted at $\mathrm{pH}$ increase from $\mathrm{pH} 2$ to $\mathrm{pH} 4$, whereas at $\mathrm{pH} 4-8$ the intensity of binding was similar (Fig. 2a). At pH > 8, BR46 decolorized spontaneously, which was verified in the preliminary study. For this reason, the results of BR46 sorption at pH 9-11 were not presented in Fig. 2a. The UV-Vis absorption spectra of the BR46 solution at pH 11 (5 min and $1440 \mathrm{~min}$ after preparing the solution) are shown in Supplement 3. 

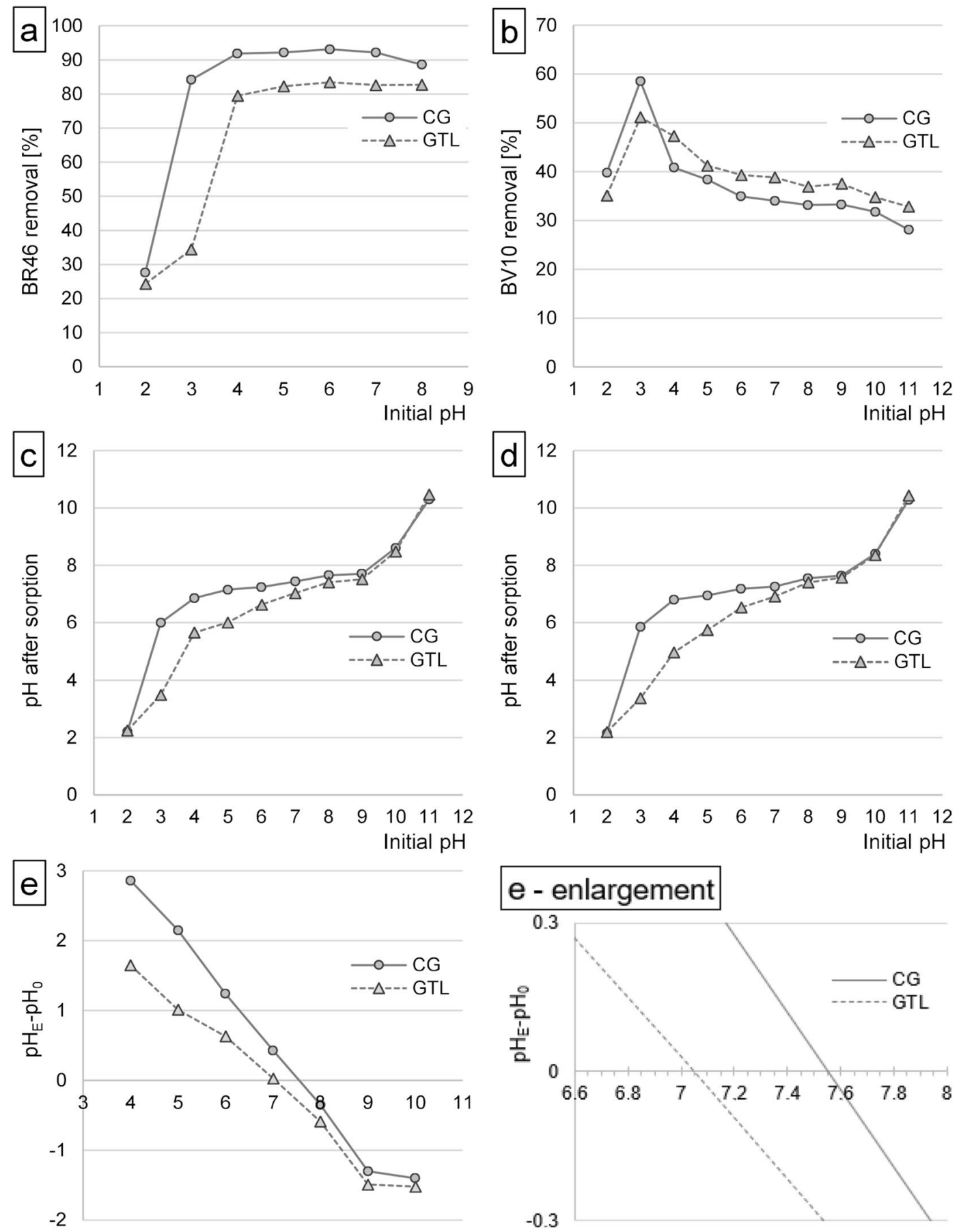

Initial $\mathrm{pH}$

Initial $\mathrm{pH}$

Figure 2. Effect of $\mathrm{pH}$ on the effectiveness of sorption of (a) BR46, and (b) BV10 onto CG and GTL. Effect of CG and GTL on changes in solution pH after sorption of: (c) BR46, and (d) BV10. (e)/e-enlargement)Determination of $\mathrm{pH}_{\mathrm{PZC}}$ of the sorbents (CG/GTL) with the Boehm's titration method. Temp. $22^{\circ} \mathrm{C}$.

The relatively low effectiveness of BR46 sorption onto CG and GTL at low $\mathrm{pH}$ was due to the protonation of the functional groups of the tested sorbents (mainly the hydroxyl groups of polysaccharide and amine groups) and to the sorbent gaining a positive charge. The positively charged surface of sorbents repulsed electrostatically BR46 cations, which significantly impaired their sorption. Presumably, at $\mathrm{pH}>4$, the effectiveness of protonation of the functional groups of CG and GTL was low, which made the sorbent lose its positive charge. In addition, at $\mathrm{pH}>4$, a significant part of the acidic functional groups (e.g., carboxyl groups) underwent deprotonation, which made the sorbent gain a negative charge, thus boosting BR46 sorption effectiveness. A similar effect of 


\begin{tabular}{|c|c|c|c|c|c|c|c|c|c|c|}
\hline \multirow[b]{3}{*}{ Sorbent } & \multirow[b]{3}{*}{ Dye } & \multirow[b]{2}{*}{ Dye conc } & \multirow[b]{2}{*}{ Equilibr. time } & \multirow{2}{*}{\begin{tabular}{|l|} 
Exp. data \\
qe. eksp
\end{tabular}} & \multicolumn{3}{|c|}{ Pseudo-first order model } & \multicolumn{3}{|c|}{ Pseudo-second order model } \\
\hline & & & & & $k_{1}$ & $\mathrm{q}_{\mathrm{e} \cdot \mathrm{cal}}$ & $\mathbf{R}^{2}$ & $\mathbf{k}_{2}$ & $\mathrm{q}_{\mathrm{e} \cdot \mathrm{cal}}$ & $\mathbf{R}^{2}$ \\
\hline & & {$[\mathrm{mg} / \mathrm{L}]$} & {$[\mathrm{min}]$} & {$[\mathrm{mg} / \mathrm{g}]$} & {$[1 / \min ]$} & {$[\mathrm{mg} / \mathrm{g}]$} & - & [g/(mg min $)]$ & {$[\mathrm{mg} / \mathrm{g}]$} & - \\
\hline \multirow{6}{*}{ CG } & \multirow{3}{*}{ BR46 } & 50 & 240 & 9.36 & 0.0814 & 9.03 & 0.9933 & 0.0135 & 9.79 & 0.9981 \\
\hline & & 200 & 240 & 37.53 & 0.0684 & 35.58 & 0.9859 & 0.0026 & 39.12 & 0.9999 \\
\hline & & 500 & 240 & 88.36 & 0.0508 & 91.96 & 0.9784 & 0.0008 & 92.48 & 0.9986 \\
\hline & \multirow{3}{*}{ BV10 } & 10 & 180 & 1.56 & 0.0505 & 1.39 & 0.9540 & 0.0443 & 1.57 & 0.9890 \\
\hline & & 50 & 240 & 7.05 & 0.0391 & 6.15 & 0.9600 & 0.0070 & 7.10 & 0.9889 \\
\hline & & 200 & 240 & 25.71 & 0.0373 & 21.91 & 0.9621 & 0.0018 & 25.44 & 0.9886 \\
\hline \multirow{6}{*}{ GTL } & \multirow{3}{*}{ BR46 } & 50 & 180 & 9.43 & 0.1225 & 9.97 & 0.9823 & \begin{tabular}{|l|l}
0.0240 \\
\end{tabular} & \begin{tabular}{|l|}
9.52 \\
\end{tabular} & 0.9987 \\
\hline & & 200 & 240 & 30.80 & 0.0839 & 27.92 & \begin{tabular}{|l|}
0.9568 \\
\end{tabular} & 0.0043 & 30.47 & 0.9912 \\
\hline & & 500 & 240 & 43.41 & \begin{tabular}{|l|l|}
0.0710 \\
\end{tabular} & 39.51 & 0.9792 & 0.0024 & 43.51 & 0.9977 \\
\hline & \multirow{3}{*}{ BV10 } & 10 & 240 & 1.72 & 0.0934 & 1.57 & 0.9681 & 0.0904 & 1.70 & 0.9954 \\
\hline & & 50 & 240 & 6.30 & 0.0696 & 5.52 & 0.9554 & 0.0172 & 6.09 & \begin{tabular}{|l|}
0.9908 \\
\end{tabular} \\
\hline & & 200 & 240 & 15.01 & 0.0588 & 12.90 & 0.9480 & 0.0058 & 14.39 & 0.9867 \\
\hline
\end{tabular}

Table 2. Kinetic parameters of BR46 and BV10 sorption onto CG and GTL determined from the pseudo-first order model and pseudo-second order model.

$\mathrm{pH}$ on BR46 sorption effectiveness was also obtained in studies into dye sorption on coconut shells ${ }^{13}$, pumpkin seed husks ${ }^{31}$, and skins of citrus fruits ${ }^{2}$.

The BV10 sorption onto CG and GTL was the most effective at $\mathrm{pH} 3$, and at the initial $\mathrm{pH}$ of 3-11 decreased along with $\mathrm{pH}$ increase. A significant decrease in BV10 sorption effectiveness was noted at $\mathrm{pH}<3$ (Fig. 2b). The untypical for cationic dyes effect of the $\mathrm{pH}$ value on the effectiveness of BV10 sorption onto CG and GTL was due to the acidic carboxyl functional group $(-\mathrm{COOH})$ of the dye. In the $\mathrm{pH}$ range of 3-8, most of the carboxyl groups of the dye occurred in the deprotonated form $\left(-\mathrm{COO}^{-}\right)$. Hence, despite generally alkaline character, BV10 molecules possessed a strong local negative charge. At low $\mathrm{pH}(\mathrm{pH} 3)$, the positively-charged surface of the sorbent entered into the electrostatic interaction with deprotonated carboxyl groups of BV10, which enhanced dye sorption. The positive charge on sorbent surface decreased with $\mathrm{pH}$ increase, which weakened interactions with -COO- groups of the dye and ultimately contributed to a lower BV10 sorption effectiveness. Under alkaline conditions $(\mathrm{pH}>8)$, the sorbent gained a negative charge, which resulted in the electrostatic repulsion between dye surface and - $\mathrm{COO}^{-}$group of BV10, additionally inhibiting dye sorption. The lower BV10 sorption effectiveness onto CG and GTL at high pH could also be due to the competition between dye molecules and $\mathrm{Na}^{+}$cations ( $\mathrm{pH}$ correction using $\mathrm{NaOH}$ ) for the sorption centers of biosorbents (mainly the hydroxyl groups of polysaccharides and lignins). The decrease in BV10 sorption effectiveness at $\mathrm{pH}<3$ could stem from the fact that at $\mathrm{pH} 2$ nearly half of the carboxyl groups lose their negative charges in an aqueous solution $\left(-\mathrm{COO}^{-}+\mathrm{H}_{3} \mathrm{O}^{+} \rightarrow-\mathrm{COOH}+\mathrm{H}_{2} \mathrm{O}\right)$, which makes the electrostatic interactions with the sorbent far weaker. The diminished effectiveness of BV 10 sorption onto CG and GTL at pH 2 could be significantly affected by the competition of - COO groups of the dye with $\mathrm{Cl}^{-}$anions ( $\mathrm{pH}$ correction using) for the active sites of the sorbent (mainly protonated hydroxyl groups).

The sorbent type (CG or GTL) did affect the dye solution $\mathrm{pH}$ during the sorption process (Fig. $2 \mathrm{c}, \mathrm{d}$ ). In the initial $\mathrm{pH}$ range of $\mathrm{pH} 4-9$, after $2 \mathrm{~h}$ of dye sorption onto $\mathrm{CG}$ the $\mathrm{pH}$ value fixed at 6.9-7.6, whereas in the case of dye sorption onto GTL-at $\mathrm{pH}$ 5.7-7.6. The $\mathrm{pH}$ changes during sorption were due to the system tending to reach the $\mathrm{pH}$ value approximating the $\mathrm{pH}$ of the point of zero charge $\left(\mathrm{pH}_{\mathrm{PZC}}\right)$. The $\mathrm{pH}_{\mathrm{PZC}}$ determined experimentally for $\mathrm{CG}$ and GTL reached $\mathrm{pH}_{\mathrm{PZC}}=7.55$ and $\mathrm{pH}_{\mathrm{PZC}}=7.05$ (Fig. 2e). The higher $\mathrm{pH}_{\mathrm{PZC}}$ value determined for $\mathrm{CG}$ may stem from a higher number of alkaline functional groups (e.g., amine groups) of this sorbent.

The kinetics of dye sorption onto CG and GTL. The time needed to reach BR46 and BV10 sorption equilibrium onto CG and GTL ranged from 180 to $240 \mathrm{~min}$ (Table 2, Supplement 4). A similar BR46 and BV10 sorption equilibrium time was noted in the study addressing dye sorption onto citrus fruit skins (180-240 min $)^{2}$. In the case of BV10, similar sorption equilibrium times were also determined for such sorbents as: coconut shells $(180 \mathrm{~min})^{13}$, jute fiber $(220 \mathrm{~min})^{32}$, or activated carbon based on Polygonum orientale biomass $(240 \mathrm{~min})^{33}$.

The sorption of dyes onto CG and GTL was the most intensive in the first minutes of the process. As soon as in the first $30 \mathrm{~min}$ of the process, the amount of dyes bound onto CG ranged from 69.6 to $83.6 \%$ and from 58.5 to $66.5 \%$ of the $\mathrm{q}_{\mathrm{e}}$ value (amount of dye sorbed after reaction equilibrium time) for BR46 and BV10, respectively. In the case of GTL, the amounts of BR46 and BV10 bound after 30 min were: $75.6-87.2 \% \mathrm{q}_{\mathrm{e}}$ and $64.6-78.5 \% \mathrm{q}_{\mathrm{e}}$.

The pseudo-second order model showed the best fit to the experimental data in each experimental series (Table 2). The $\mathrm{q}_{\mathrm{e} \text { cal }}$ values ( $\mathrm{q}_{\mathrm{e}}$-equilibrium amount of sorbed dye) calculated from the models increased along with a higher initial dye concentration, which can be explained by the increasing likelihood of sorbate collisions with sorption centers. In contrast to $\mathrm{q}_{\mathrm{e}}$, the values of sorption rate constants $\left(\mathrm{k}_{2}\right)$ decrease along with dye concentration increase, typically of basic dye sorption onto biosorbents ${ }^{2,31,34}$.

In order to distinguish and describe particular phases of the sorption process, the experimental data obtained were described using the intramolecular diffusion model. The graphs plotted using this model suggest that the sorption of both BV10 and BR46 onto CG and GTL always proceeds in three phases (Fig. 3). In the first, the shortest, and the most intensive phase of the sorption, dye molecules probably attached to the most available 

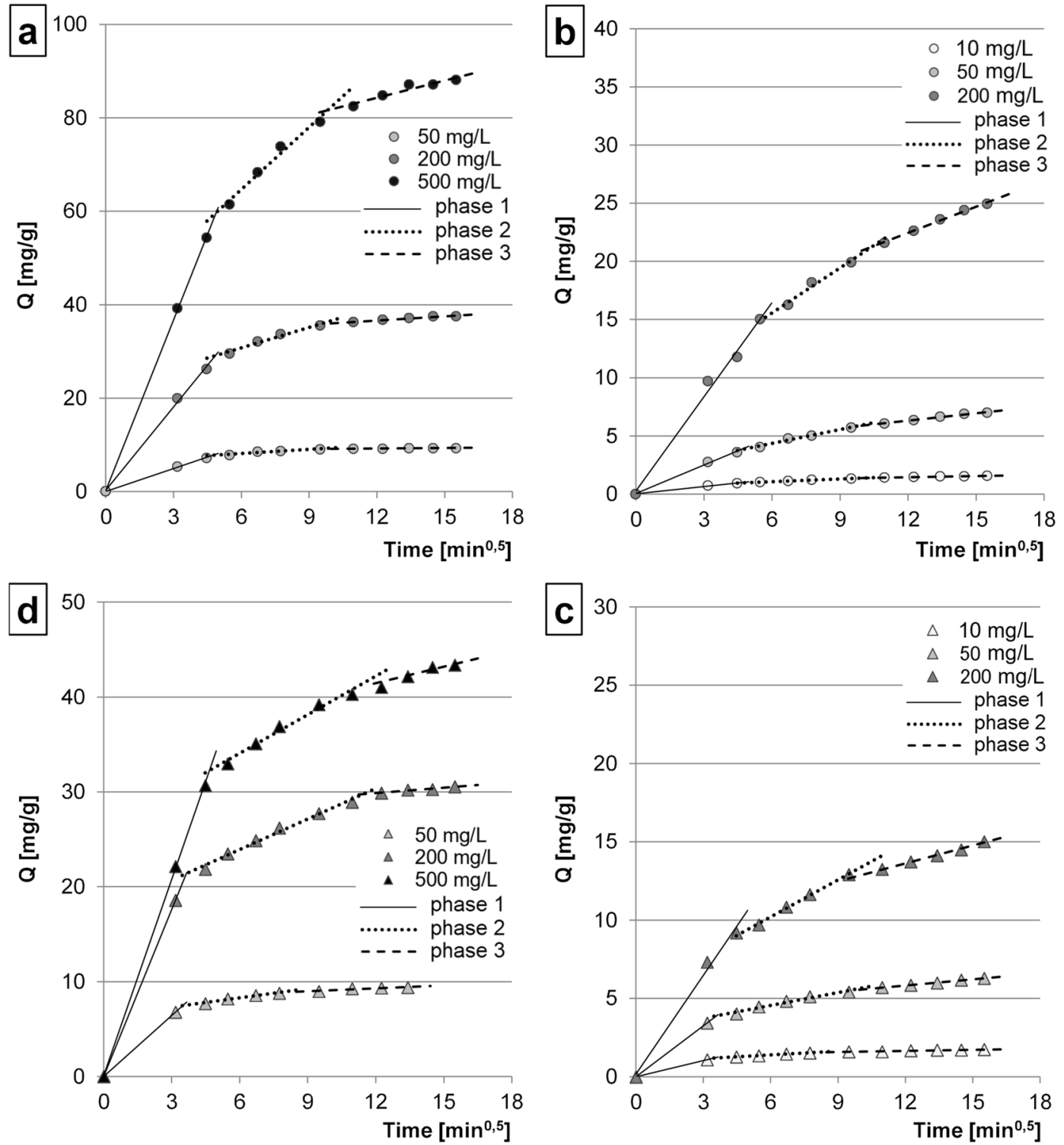

Figure 3. The intramolecular diffusion model of sorption of: (a) BR46 onto CG; (b) BV10 onto CG; (c) BR46 onto GTL; and (d) BV10 onto GTL. Temp. $22^{\circ} \mathrm{C}$.

active sites of the biosorbent, located mainly on its surface ${ }^{34}$. The second phase began once the easily available sorption centers depleted on the sorbent surface. In this phase, dye molecules occupied mainly the active sites located in the less accessible regions of the sorbent. In addition, this phase was much longer and characterized by a lower sorption intensity and by significantly greater competition between dye molecules for the active sites ${ }^{35}$, compared to the first phase. In the third, the longest and the least effective phase, the last free sorption centers were depleted (Fig. 3, Table 3).

The first key phase of dye sorption onto CG lasted $20 \mathrm{~min}$ in most experimental variants (Table 3), being longer (30 min) only at the highest BV10 concentration. In the case of GTL, the first phase of the sorption lasted from $10 \mathrm{~min}$ at the lower initial dye concentrations to $20 \mathrm{~min}$ at the higher initial concentrations of BR46/BV10. The increase in the $\mathrm{k}_{\mathrm{d} 1}, \mathrm{k}_{\mathrm{d} 2}$ and $\mathrm{k}_{\mathrm{d} 3}$ values observed in each sorption phase along with a higher initial concentration of both BR46 and BV10 was, presumably, due to the increasing availability of sorbate molecules in the solution and the higher likelihood of their collisions with the sorption centers.

The more effective sorption of BR46 onto CG and GTL compared to BV10 could stem from various sorption $\mathrm{pHs}$ and molecular weight of the dyes (BV10-479 g/mol, BR46-322 g/mol). The smaller sizes of Basic Red 46 molecules were probably reflected in its better capability for penetrating sorbent structure and reaching sorption centers located in its deeper, less available layers. The differences in dye sorption effectiveness could also be significantly affected by differences in their structure and various functional groups they possessed. Apart from methyl groups $\left(-\mathrm{CH}_{3}\right)$ typical of BR46, BV10 possesses an acidic carboxyl group $\left(-\mathrm{COOH}^{-}\right)$untypical of cationic dyes, which makes it attain some features of anionic dyes. 


\begin{tabular}{|c|c|c|c|c|c|c|c|c|c|c|c|}
\hline \multirow[b]{2}{*}{ Sorbent } & \multirow[b]{2}{*}{ Dye } & \multirow[b]{2}{*}{ Dye conc. $[\mathrm{mg} / \mathrm{L}]$} & \multicolumn{3}{|c|}{ Phase 1} & \multicolumn{3}{|c|}{ Phase 2} & \multicolumn{3}{|c|}{ Phase 3} \\
\hline & & & $\mathbf{k}_{\mathrm{d} 1}$ & Duration & $\mathbf{R}^{2}$ & $k_{\mathrm{d} 2}$ & Duration & $\mathbf{R}^{2}$ & $k_{\mathrm{d} 2}$ & Duration & $\mathbf{R}^{2}$ \\
\hline \multirow{6}{*}{ CG } & \multirow{3}{*}{ BR46 } & 50 & 1.636 & $\sim 20$ & 0.9989 & 0.298 & $\sim 100$ & 0.8942 & 0.040 & $\sim 120$ & 0.9431 \\
\hline & & 200 & 5.953 & $\sim 20$ & 0.9966 & 1.458 & $\sim 100$ & 0.9708 & 0.300 & $\sim 120$ & 0.9577 \\
\hline & & 500 & 12.196 & $\sim 20$ & 0.9997 & 4.442 & $\sim 100$ & 0.9767 & 1.230 & $\sim 120$ & 0.9191 \\
\hline & \multirow{3}{*}{ BV10 } & 10 & 0.206 & $\sim 20$ & 0.9921 & 0.077 & $\sim 70$ & 0.9856 & 0.031 & $\sim 150$ & 0.9598 \\
\hline & & 50 & 0.816 & $\sim 20$ & 0.9950 & 0.397 & $\sim 70$ & 0.9696 & 0.214 & $\sim 150$ & 0.9761 \\
\hline & & 200 & 2.702 & $\sim 30$ & 0.9907 & 1.294 & $\sim 60$ & 0.9701 & 0.750 & $\sim 150$ & 0.9961 \\
\hline \multirow{6}{*}{ GTL } & \multirow{3}{*}{ BR46 } & 50 & 2.142 & $\sim 10$ & 0.9999 & 0.323 & $\sim 50$ & 0.9602 & 0.101 & $\sim 120$ & 0.8930 \\
\hline & & 200 & 5.867 & $\sim 10$ & 0.9999 & 1.077 & $\sim 110$ & 0.9856 & 0.188 & $\sim 120$ & 0.9530 \\
\hline & & 500 & 6.884 & $\sim 20$ & 0.9997 & 1.356 & $\sim 100$ & 0.9781 & 0.584 & $\sim 120$ & 0.8926 \\
\hline & \multirow{3}{*}{ BV10 } & 10 & 0.346 & $\sim 10$ & 0.9999 & 0.079 & $\sim 50$ & 0.9831 & 0.024 & $\sim 180$ & 0.9770 \\
\hline & & 50 & 1.084 & $\sim 10$ & 0.9999 & 0.275 & $\sim 80$ & 0.9683 & 0.131 & $\sim 150$ & 0.9928 \\
\hline & & 200 & 2.103 & $\begin{array}{l}\sim 20 \\
\end{array}$ & 0.9909 & \begin{tabular}{|l|}
0.790 \\
\end{tabular} & $\sim 70$ & 0.9961 & 0.381 & $\sim 150$ & \begin{tabular}{|l|}
0.9918 \\
\end{tabular} \\
\hline
\end{tabular}

Table 3. Rate constants of BR46 and BV10 diffusion determined from a simplified intramolecular diffusion model. Units: $\mathrm{k}_{\mathrm{d} 1}, \mathrm{k}_{\mathrm{d} 2}, \mathrm{k}_{\mathrm{d} 3}=\left[\mathrm{mg} \mathrm{g}^{-1} \min ^{-0,5}\right]$, duration [min], $\mathrm{R}^{2}[-]$.

\begin{tabular}{|c|c|c|c|c|c|c|c|c|c|c|c|c|c|}
\hline \multirow[b]{3}{*}{ Sorbent } & \multirow[b]{3}{*}{ Dye } & \multicolumn{3}{|c|}{ Langmuir 1} & \multicolumn{6}{|c|}{ Langmuir 2} & \multicolumn{3}{|c|}{ Freundlich } \\
\hline & & $\mathbf{Q}_{\max }$ & $\mathbf{K}_{\mathrm{c}}$ & $\mathbf{R}^{2}$ & $\mathbf{Q}_{\max }$ & $b_{1}$ & $\mathrm{~K}_{1}$ & $b_{2}$ & $\mathrm{~K}_{2}$ & $\mathbf{R}^{2}$ & $\mathbf{K}$ & $\mathbf{n}$ & $\mathbf{R}^{2}$ \\
\hline & & {$[\mathrm{mg} / \mathrm{g}]$} & {$[\mathrm{L} / \mathrm{mg}]$} & - & {$[\mathrm{mg} / \mathrm{g}]$} & {$[\mathrm{mg} / \mathrm{g}]$} & {$[\mathrm{L} / \mathbf{m g}]$} & {$[\mathrm{mg} / \mathrm{g}]$} & {$[\mathrm{L} / \mathrm{mg}]$} & - & - & - & - \\
\hline \multirow{2}{*}{ CG } & BR46 & 165.85 & 0.022 & 0.995 & 179.36 & 99.47 & 0.036 & 79.89 & 0.008 & 0.996 & 14.2 & 0.43 & 0.950 \\
\hline & BV10 & 59.32 & 0.009 & 0.998 & 59.32 & 34.44 & 0.009 & 24.89 & 0.009 & 0.998 & 2.2 & 0.54 & 0.975 \\
\hline \multirow{2}{*}{ GTL } & BR46 & 48.73 & 0.046 & 0.976 & 57.98 & 30.69 & 0.133 & 27.28 & 0.004 & 0.999 & 10.0 & 0.26 & 0.981 \\
\hline & BV10 & 23.41 & 0.016 & 0.978 & 26.66 & 22.73 & 0.017 & 3.93 & 0.004 & 0.998 & 2.2 & 0.38 & 0.987 \\
\hline
\end{tabular}

Table 4. Constants determined from the Langmuir 1 model, Langmuir 2 model, and Freundlich model.

The maximal sorption capacity of CG and GTL. The experimental data, obtained in the analyses of the maximal sorption capacity, were described using popular sorption models, i.e.: Langmuir isotherm, double Langmuir isotherm (Langmuir 2 model), and Freundlich isotherm (Table 4, Supplement 5). The analysis of the coefficient of determination $\left(\mathrm{R}^{2}\right)$ values indicated that the sorption of BR46 and BV10 onto CG and GTL was better described by the Langmuir and Langmuir 2 models than by the Freundlich model. The better fit of experimental data to the Langmuir and Langmuir 2 models than to the Freundlich model points to dye binding onto the sorbent in the form of a monolayer, where dye molecules may change their positions (i.e., "switch" their active sites).

The sorption of BR46 onto CG and GTL and the sorption of BV10 onto GTL were best described by the Langmuir 2 model, which implies an important role of more than one type of the active sites in the process or various modes of dye binding with the sorption center. Presumably, the hydroxyl functional groups derived from polysaccharides (cellulose/hemicellulose), located on the sorbent surface, served as the first type of the active sites. In turn, both amine groups and hydroxyl groups located in deeper, less accessible sorbent layers, could serve as the second type of sorption centers. A significant role in BR46 sorption could also be ascribed to the carboxyl groups. In addition, the dyes tested could bind with the functional groups of the sorbents also by means of hydrogen bridges. In case of BV10 sorption onto CG, the $\mathrm{K}_{\mathrm{c}}$ constants computed from the Langmuir model and the $K_{1}$ and $K_{2}$ constants calculated from the Langmuir 2 model have the same values, which may suggest that one type of active sites was responsible for this dye sorption onto CG. Presumably, this role was played by the protonated amine groups of CG. No similar result was observed for GTL due to a lower number of alkaline (amine) functional groups, as mentioned during the analysis of the $\mathrm{pH}_{\mathrm{PZC}}$ values of the sorbents ("The effect of $\mathrm{pH}$ on the effectiveness of dye sorption onto CG and GTL" section).

Compared to BV10, BR46 showed generally greater affinity to the functional groups of CG and GTL, as evidenced by higher values of $K_{c}, K_{1}$, and $K_{2}$ constants. The sorbents tested also show higher sorption capacity of BR46 than of BV10 (Table 4). As mentioned in "The kinetics of dye sorption onto CG and GTL" section, the differences observed in dye sorption capacity could be due the various nature of functional groups of the dyes, different sorption conditions ( $\mathrm{pH} 3$ for BV10 and $\mathrm{pH} 6$ for BR46), and also various molecular weights of dyes (BV10-479 g/mol, BR46-322 $\mathrm{g} / \mathrm{mol}$ ). The smaller dimensions of BR46 molecules facilitate sorbent structure penetration and occupation of a higher number of sorption centers available in the sorbent, which explains higher BR46 sorption effectiveness.

The better BR46 sorption properties of CG compared to GTL could be attributed to a higher number of carboxyl functional groups, as demonstrated during FTIR spectra analysis ("The kinetics of dye sorption onto CG and GTL" section). In turn, the higher effectiveness of BV10 sorption onto CG than GTL could be due to a 


\begin{tabular}{|c|c|c|c|c|c|}
\hline Dye & Sorbent & Sorption capacity [mg/g] & Sorption $\mathrm{pH}[\mathrm{pH}]$ & Sorption time [min] & Source \\
\hline \multirow{14}{*}{ BR46 } & Beech sawdust & 19.2 & - & - & 39 \\
\hline & Fir sawdust & 20.5 & - & - & 39 \\
\hline & Walnut sawdust & 30.1 & 7 & - & 40 \\
\hline & Paulownia tomentosa tree leaves & 43.1 & 8 & 70 & 22 \\
\hline & Active carbon ROW 08 & 45.0 & 8 & 60 & 41 \\
\hline & Rape seed husks & 49.0 & 8 & 10 & 42 \\
\hline & Lemon skin & 54.0 & 6 & 240 & 2 \\
\hline & Mandarin skin & 54.2 & 6 & 240 & 2 \\
\hline & Spent green tea leaves & 58.0 & 6 & 240 & This work \\
\hline & Active carbon from the Cerbera biomass & 65.7 & 7 & 90 & 36 \\
\hline & Coconut shells & 68.5 & 6 & 120 & 13 \\
\hline & Pine leaves & 71.9 & 6 & 75 & 43 \\
\hline & Pine cones & 73.5 & 8 & 75 & 44 \\
\hline & Spent coffee grounds & 179.4 & 6 & 240 & This work \\
\hline \multirow{16}{*}{ BV10 } & Coal-fired coconut fiber & 2.6 & 6.5 & 150 & 45 \\
\hline & Mango leaves (powder) & 3.3 & - & 48 & 46 \\
\hline & Calotropis procera leaf biomass & 4.1 & - & 60 & 47 \\
\hline & Cedar cones & 4.6 & - & 360 & 39 \\
\hline & Grapefruit skin & 4.6 & 3 & 240 & 2 \\
\hline & Lemon skin & 5.7 & 3 & 240 & 2 \\
\hline & Sugar cane fiber & 10.4 & - & - & 48 \\
\hline & Coconut fiber & 16.5 & 7 & 90 & 49 \\
\hline & Active fiber from walnut shell & 18.7 & - & - & 37 \\
\hline & Banana skin & 20.6 & 6 & 1440 & 50 \\
\hline & Spent green tea leaves & 26.7 & 3 & 240 & This work \\
\hline & Active carbon from jute fiber & 28.0 & 8 & 220 & 32 \\
\hline & Coconut shells & 28.5 & 3 & 180 & 13 \\
\hline & Active carbon from palm bark & 30.0 & 3 & - & 51 \\
\hline & Spent coffee grounds & 59.3 & 3 & 240 & This work \\
\hline & Commercial active carbon powder & 72.5 & 4 & 1440 & 38 \\
\hline
\end{tabular}

Table 5. Sorption capacity of various unconventional biosorbents and activated carbons towards BV 10 and BR46.

higher number of alkaline (amine) functional groups on CG, which was confirmed by the $\mathrm{pH}_{\mathrm{PZC}}$ values of the sorbents ("The effect of $\mathrm{pH}$ on the effectiveness of dye sorption onto CG and GTL" section). The higher sorption capacity of CG than of GTL can also stem from the partial carbonization of coffee grain during their "roasting", which could contribute to significant enlargement of sorbent surface, thereby increasing its sorption capacity.

Table 5 collates sorption capacities of various unconventional sorbents and activated carbons towards dyes tested in this research, i.e. BR46 and BV10. The sorbents analyzed in the present study (CG and GTL) demonstrated higher sorption capacity of cationic dyes BR46 and BV10 than biosorbents based on fruit skins, tree leaves, and sawdust (Table 5). What is more, dye sorption effectiveness was higher on CG compared to activated carbons produced from lignocellulosic plant biomass ${ }^{32,36,37}$ and was inferior only to the high-quality commercial activated carbon ${ }^{38}$.

\section{Summary}

Appropriately prepared spent coffee ground and spent green tea leaves may serve as effective sorbents of cationic dyes. In the case of dyes tested, i.e. BR46 and BV10, the maximal sorption capacity of these sorbents reached: $179.4 \mathrm{mg} / \mathrm{g}$ and $59.3 \mathrm{mg} / \mathrm{g}$ for CG and $58.0 \mathrm{mg} / \mathrm{g}$ and $26.7 \mathrm{mg} / \mathrm{g}$ for GTL, respectively.

The effectiveness of BV10 and BR46 binding onto CG and GTL was significantly determined by the pH value of the sorption solution. Despite the similar nature of both dyes (basic dyes), they required various $\mathrm{pH}$ values to reach the maximum sorption capacity. The sorption of BV10 onto CG and GTL was the most effective at $\mathrm{pH}$ 3, whereas that of BR46-at $\mathrm{pH}$ 6. The relatively low $\mathrm{pH}$ value of $\mathrm{BV} 10$ dye sorption ( $\mathrm{pH} 3$ ) was due to its acidic carboxyl functional group (-COOH). Both CG and GTL caused changes in solution $\mathrm{pH}$ during the sorption process, due to the system tending to reach the $\mathrm{pH}$ value approximating the $\mathrm{pH}$ zero point charge $\left(\mathrm{pH}_{\mathrm{PZC}}=7.55\right.$ for $\mathrm{CG}$ and $\mathrm{pH}_{\mathrm{PZC}}=7.05$ for $\mathrm{GTL}$ ).

The effectiveness of BR46 sorption onto CG and GTL was higher than that of BV10, which was due to the various functional groups of the dyes, different sorption $\mathrm{pHs}$, and different molecular weights of the dyes (BR46-322 g/mol, BV10-479 g/mol). The smaller molecules of BR46 compared to BV10 allowed its easier penetration into sorbent structure and its access to the less available sorption centers. 
The better sorption capabilities of GC compared to GTL can be due to a higher number of carboxyl functional groups and greater specific area gained during coffee grain "roasting".

The time needed to reach BR46 and BV10 sorption equilibrium onto CG and GTL was similar and ranged from 180 to $240 \mathrm{~min}$. However, the intensity of dye sorption increased along with a higher initial dye concentration, especially in the first minutes of the process. This could be attributed to a high number of dye molecules in the solution and higher probability of their collisions with sorption centers.

The experimental data concerning the kinetics of BR46 and BV10 sorption onto CG and GTL were the best described with the pseudo-second order model, which is typical of the sorption of cationic dyes on biosorbents.

The sorption of BR46 and BV10 onto CG and GTL proceeded in three main phases. In the first, the shortest, and the most intensive phase, dye molecules occupied the most available sorption sites located mainly on sorbent surface. In the second, much longer, and less intensive phase, the saturation of the sorption centers was mainly observed in less available sorbent regions. In the third, the longest, and the least intensive phase, dye molecules slowly attached to the last free active sites of the sorbent.

The sorption of BR46 and BV10 onto CG and GTL was better described by the Langmuir 1 and Langmuir 2 models than by the Freundlich model, which points to dye binding onto the sorbent in the form of a monolayer, where dye molecules may change their positions (they can "switch" their active sites). The better fit of the Langmuir 2 than the Langmuir 1 model to the experiment data of BR46 sorption onto CG and GTL and BR46 sorption onto GTL implies an important role of more than one type of the active sites in the process or various modes of dye binding with the sorption center. Hydroxyl, carboxyl, and amine group are the active sites of sorbents that may play a significant role in the sorption process of cationic dyes. In the case of BV10 sorption onto CG, the $\mathrm{K}_{\mathrm{c}}$ constants computed from the Langmuir model and the $\mathrm{K}_{1}$ and $\mathrm{K}_{2}$ constants computed from the Langmuir 2 model had the same values, which may suggest that only one type of active sites (probably the protonated amine groups) was responsible for its sorption onto CG.

Received: 8 March 2021; Accepted: 20 April 2021

Published online: 05 May 2021

\section{References}

1. Annadurai, G., Juang, R. S. \& Lee, D. J. Use of cellulose-based wastes for adsorption of dyes from aqueous solutions. J. Hazard. Mater. 92, 263-274 (2002).

2. Jóźwiak, T., Filipkowska, U. \& Zajko, P. Use of citrus fruit peels (grapefruit, mandarin, orange, and lemon) as sorbents for the removal of Basic Violet 10 and Basic Red 46 from aqueous solutions. Desalin. Water Treat. 163, 385 (2019).

3. Nhung, N. T. H., Quynh, B. T. P., Thao, P. T. T., Bich, H. N. \& Giang, B. L. Pretreated fruit peels as adsorbents for removal of dyes from water. IOP Conf. Ser. Earth Environ. Sci. 159, 012015 (2018).

4. Enniya, I. \& Jourani, A. Study of methylene blue removal by a biosorbent prepared with apple peels. J. Mater. Environ. Sci. 8, 4573-4581 (2017).

5. Stavrinou, A., Aggelopoulos, C. A. \& Tsakiroglou, C. D. Exploring the adsorption mechanisms of cationic and anionic dyes onto agricultural waste peels of banana, cucumber and potato: Adsorption kinetics and equilibrium isotherms as a tool. J. Environ. Chem. Eng. 6, 6958-6970 (2018).

6. Bouhadjra, K., Lemlikchi, W., Ferhati, A. \& Mignard, S. Enhancing removal efficiency of anionic dye (Cibacron blue) using waste potato peels powder. Sci. Rep. https://doi.org/10.1038/s41598-020-79069-5 (2021).

7. Bayomie, O. S. et al. Novel approach for effective removal of methylene blue dye from water using fava bean peel waste. Sci. Rep. https://doi.org/10.1038/s41598-020-64727-5 (2020).

8. Vyavahare, G. et al. Strategies for crystal violet dye sorption on biochar derived from mango leaves and evaluation of residual dye toxicity. J. Clean. Prod. 207, 296-305 (2019).

9. Hameed, B. H., Mahmoud, D. K. \& Ahmad, A. L. Sorption equilibrium and kinetics of basic dye from aqueous solution using banana stalk waste. J. Hazard. Mater. 158, 499-506 (2008).

10. Crini, G. Non-conventional low-cost adsorbents for dye removal: A review. Bioresour. Technol. 97, 1061-1085 (2006).

11. Etorki, A. M. \& Massoudi, F. M. N. The use of peanut hull for the adsorption of colour from aqueous dye solutions and dye textile effluent. Orient. J. Chem. 27, 875-884 (2011).

12. Kaya, N., Yıldız, Z. \& Ceylan, S. Preparation and characterisation of biochar from hazelnut shell and its adsorption properties for methylene blue dye. J. Polytech. https://doi.org/10.2339/politeknik.386963 (2018).

13. Józwiak, T., Filipkowska, U., Bugajska, P. \& Kalkowski, T. The use of coconut shells for the removal of dyes from aqueous solutions. J. Ecol. Eng. https://doi.org/10.12911/22998993/89672 (2018).

14. Kocaman, S. Removal of methylene blue dye from aqueous solutions by adsorption on levulinic acid-modified natural shells. Int. J. Phytoremediat. 22, 885-895 (2020).

15. Quansah, J. O. et al. Nascent rice husk as an adsorbent for removing cationic dyes from textile wastewater. Appl. Sci. 10, 3437 (2020).

16. Das, S., Singh, S. \& Garg, S. Evaluation of wheat bran as a biosorbent for potential mitigation of dye pollution in industrial waste waters. Orient. J. Chem. 35, 1565-1573 (2019).

17. Banerjee, S. et al. Removal of Malachite Green, a hazardous dye from aqueous solutions using Avena sativa (oat) hull as a potential adsorbent. J. Mol. Liq. 213, 162-172 (2016)

18. Gruczyńska, E., Kowalska, D., Kozłowska, M., Majewska, E. \& Tarnowska, K. Furan in roasted, ground and brewed coffee. Rocz. Panstw. Zakl. Hig. 69, 111-118 (2018).

19. Prasanth, M. I., Sivamaruthi, B. S., Chaiyasut, C. \& Tencomnao, T. A review of the role of green tea (Camellia sinensis) in antiphotoaging, stress resistance, neuroprotection, and autophagy. Nutrients 11, 474 (2019).

20. Ballesteros, L. F., Teixeira, J. A. \& Mussatto, S. I. Chemical, functional, and structural properties of spent coffee grounds and coffee silverskin. Food Bioprocess. Technol. 7, 3493-3503 (2014).

21. Rahman, N. H. A., Chieng, B. W., Ibrahim, N. A. \& Rahman, N. A. Extraction and characterization of cellulose nanocrystals from tea leaf waste fibers. Polymers (Basel) 9, 588 (2017).

22. Deniz, F. \& Saygideger, S. D. Removal of a hazardous azo dye (Basic Red 46) from aqueous solution by princess tree leaf. Desalination 268, 6-11 (2011).

23. Hassani, A. et al. Enhanced removal of basic violet 10 by heterogeneous sono-Fenton process using magnetite nanoparticles. Ultrason. Sonochem. 42, 390-402 (2018). 
24. Sivakumar, S. et al. FT-IR study of green tea leaves and their diseases of Arunachal Pradesh, North East, India. Pharm. Chem. J. 1, $17-24$ (2014).

25. Li, X. et al. Rapid determination of chlorophyll and pheophytin in green tea using fourier transform infrared spectroscopy. Molecules https://doi.org/10.3390/molecules23051010 (2018).

26. Craig, A. P., Franca, A. S. \& Oliveira, L. S. Evaluation of the potential of FTIR and chemometrics for separation between defective and non-defective coffees. Food Chem. https://doi.org/10.1016/j.foodchem.2011.11.121 (2012).

27. Lionetto, F., Del Sole, R., Cannoletta, D., Vasapollo, G. \& Maffezzoli, A. Monitoring wood degradation during weathering by cellulose crystallinity. Materials (Basel). https://doi.org/10.3390/ma5101910 (2012).

28. Monje, A. F. B., Parrado, L. X. \& Gutiérrez-Guzmán, N. ATR-FTIR for disc rimenation of espresso and americano coffee pods. Coffee Sci. https://doi.org/10.25186/cs.v13i4.1499 (2018).

29. Zhang, Z. P., Rong, M. Z., Zhang, M. Q. \& Yuan, C. Alkoxyamine with reduced homolysis temperature and its application in repeated autonomous self-healing of stiff polymers. Polym. Chem. https://doi.org/10.1039/c3py00679d (2013).

30. Nandiyanto, A. B. D., Oktiani, R. \& Ragadhita, R. How to read and interpret ftir spectroscope of organic material. Indones. J. Sci. Technol. https://doi.org/10.17509/ijost.v4i1.15806 (2019).

31. Kowalkowska, A. \& Jóźwiak, T. Utilization of pumpkin (Cucurbita pepo) seed husks as a low-cost sorbent for removing anionic and cationic dyes from aqueous solutions. Desalin. Water Treat. 171, 397-407 (2019).

32. Porkodi, K. \& Vasanth Kumar, K. Equilibrium, kinetics and mechanism modeling and simulation of basic and acid dyes sorption onto jute fiber carbon: Eosin yellow, malachite green and crystal violet single component systems. J. Hazard. Mater. 143, 311-327 (2007).

33. Wang, L. et al. Adsorption of basic dyes on activated carbon prepared from Polygonum orientale Linn: Equilibrium, kinetic and thermodynamic studies. Desalination 254, 68-74 (2010).

34. Kumar, R. \& Ahmad, R. Biosorption of hazardous crystal violet dye from aqueous solution onto treated ginger waste (TGW). Desalination 265, 112-118 (2011).

35. Kulkarni, M. R., Revanth, T., Acharya, A. \& Bhat, P. Removal of crystal violet dye from aqueous solution using water hyacinth: Equilibrium, kinetics and thermodynamics study. Resour. Technol. 3, 71-77 (2017).

36. Azmi, N. A. I., Zainudin, N. F. \& Ali, U. F. M. Adsorption of basic Red 46 using sea mango (Cerbera odollam) based activated carbon. AIP Conf. Proc. 1660, 070068 (2015).

37. Sumanjit Walia, T. P. S. \& Kansal, I. Removal of Rhodamine-B by adsorption on walnut shell charcoal. J. Surf. Sci. Technol. 24, 179-193 (2008).

38. Filipkowska, U., Jóźwiak, T., Szymczyk, P. \& Kuczajowska-Zadrożna, M. The use of active carbon immobilised on chitosan beads for RB5 and BV10 dye removal from aqueous solutions. Prog. Chem. Appl. Chitin iIs Deriv. 22, 14-26 (2017).

39. Zamouche, M. \& Hamdaoui, O. Sorption of Rhodamine B by cedar cone: Effect of pH and ionic strength. Energy Procedia 18, 1228-1239 (2012).

40. Yeddou, N. \& Bensmaili, A. Kinetic models for the sorption of dye from aqueous solution by clay-wood sawdust mixture. Desalination 185, 499-508 (2005).

41. Madeła, M. D. \& Krzemińska, E. N. Wpływ procesu Fentona na skuteczność usuwania zanieczyszczeń ze ścieków przemysłowych na węglach aktywnych. Technol. Wody 5, 46-50 (2014).

42. Mahmoodi, N. M., Arami, M., Bahrami, H. \& Khorramfar, S. Novel biosorbent (Canola hull): Surface characterization and dye removal ability at different cationic dye concentrations. Desalination 264, 134-142 (2010).

43. Deniz, F., Karaman, S. \& Saygideger, S. D. Biosorption of a model basic dye onto Pinus brutia Ten.: Evaluating of equilibrium, kinetic and thermodynamic data. Desalination 270, 199-205 (2011).

44. Deniz, F. \& Karaman, S. Removal of basic red 46 dye from aqueous solution by pine tree leaves. Chem. Eng. J. 170, 67-74 (2011).

45. Namasivayam, C. et al. 'Waste' coir pith-A potential biomass for the treatment of dyeing wastewaters. Biomass Bioenergy 21, 477-483 (2001).

46. Hussain-Gardazi, S. M. et al. Effective adsorption of cationic dye from aqueous solution using low-cost corncob in batch and column studies. Desalin. Water Treat. 57, 28981-28998 (2016).

47. Ali, H. \& Muhammad, S. K. Biosorption of crystal violet from water on leaf biomass of Calotropis procera. J. Environ. Sci. Technol. 1, 143-150 (2008).

48. Parab, H., Sudersanan, M., Shenoy, N., Pathare, T. \& Vaze, B. Use of agro-industrial wastes for removal of basic dyes from aqueous solutions. Clean: Soil, Air, Water 37, 963-969 (2009).

49. Sureshkumar, M. V. \& Namasivayam, C. Adsorption behavior of Direct Red 12B and Rhodamine B from water onto surfactantmodified coconut coir pith. Colloids Surf. A Physicochem. Eng. Asp. 317, 277-283 (2008).

50. Namasivayam, C., Kanchana, N. \& Yamuna, R. T. Waste banana pith as adsorbent for the removal of rhodamine-B from aqueous solutions. Waste Manage. 13, 89-95 (1993).

51. Mohammadi, M., Hassani, A. J., Mohamed, A. R. \& Najafpour, G. D. Removal of rhodamine b from aqueous solution using palm shell-based activated carbon: Adsorption and kinetic studies. J. Chem. Eng. Data 55, 5777-5785 (2010).

\section{Acknowledgements}

This study was financed under Project No. 18.610.008-300 of the University of Warmia and Mazury in Olsztyn, Poland.

\section{Author contributions}

T.J.-Conceptualization, Supervision, Writing/Original Draft; U.F.-Writing/Review \& Editing, Formal analysis, Resources; J.S.-S.-Writing/Review \& Editing, Formal analysis; K.B.-Writing/Review \& Editing; Investigation, Data Curation; K.T.-Investigation, Data Curation; J.K.-Investigation, Data Curation; M.Ś.-Investigation, Data Curation.

\section{Competing interests}

The authors declare no competing interests.

\section{Additional information}

Supplementary Information The online version contains supplementary material available at https://doi.org/ 10.1038/s41598-021-89095-6.

Correspondence and requests for materials should be addressed to T.J.

Reprints and permissions information is available at www.nature.com/reprints. 
Publisher's note Springer Nature remains neutral with regard to jurisdictional claims in published maps and institutional affiliations.

(c) (i) Open Access This article is licensed under a Creative Commons Attribution 4.0 International License, which permits use, sharing, adaptation, distribution and reproduction in any medium or format, as long as you give appropriate credit to the original author(s) and the source, provide a link to the Creative Commons licence, and indicate if changes were made. The images or other third party material in this article are included in the article's Creative Commons licence, unless indicated otherwise in a credit line to the material. If material is not included in the article's Creative Commons licence and your intended use is not permitted by statutory regulation or exceeds the permitted use, you will need to obtain permission directly from the copyright holder. To view a copy of this licence, visit http://creativecommons.org/licenses/by/4.0/.

(C) The Author(s) 2021 